\title{
Geomorfología y paisaje en el ordenamiento territorial: valorizando el corredor inferior del río Mapocho ${ }^{1}$
}

\author{
Francisco J. Ferrando Acuña² fferrand@uchilefau.cl, Franco de Luca N³ .
}

\begin{abstract}
RESUMEN
Considerando las funciones de corredor biológico del sistema hidrológico inferior del Río Mapocho, y apuntando a su integración a la planificación urbana de la intercomuna respectiva desde un punto de vista ecológico-ambiental y social, se reconocen sus características geomorfológicas y paisajísticas, y se establecen los procesos que lideran la evolución del modelado de las formas naturales. Con esta base se delimita el territorio fluvial desde una perspectiva ecosistémica y se determinan los límites de las diferentes unidades homogéneas resultantes. Cada unidad geomorfológica, en alta correspondencia con el sistema de paisajes, es caracterizada en función de su geología, sedimentología, suelos y drenaje, hidro-morfodinámica e intervención humana, lo cual permite mediante la determinación de la calidad y fragilidad de ellas, establecer propuestas de uso del suelo con sus correspondientes alcances sobre aptitudes y restricciones. La cartografía resultante contiene implícita una propuesta de ordenamiento del territorio desde el punto de vista de la planificación ecológica.
\end{abstract}

Palabras clave: Corredor fluvial; Geomorfología; Paisaje; Aptitudes de uso; Ordenamiento territorial; Planificación ecológica.

\section{Territorial planning, geomorphology and landscape: enhancing the Rio Mapocho lower corridor}

\begin{abstract}
Considering the roles how biological corridor of the lower hydrological system of the Mapocho River, pointing to their integration in the urban planning of the respective communes from an ecologic, environmental and social perspective, is carried on a research about their geomorphological and landscape characteristics and the processes that are leading the evolution of the landscape. With this knowledge and from an ecosystemic perspective of the river territory, the limits of different homogeneous units were determined. Any geomorphological unit recognized, meaning also landscape systems, was characterized by its geology, sedimentology, soils and drainage, hydro-morphodynamic processes and human intervention, which allows through the determination of the quality and fragility of the geomorphic-landscape units, to establish land use proposals with their corresponding scopes on qualifications and restrictions. The resulting mapping contains implicit a proposal for land-use planning from the ecological planning point of view.
\end{abstract}

Key words: Fluvial corridor; Geomorphology; Landscape; Land use aptitudes; Territorial ordering; Ecological planning.

Recibido el 11 de enero de 2011, aceptado el 9 de septiembre de 2011

\footnotetext{
Proyecto FONDECYT 1090199

Departamento de Geografía, Universidad de Chile, Portugal 084, Santiago, R.M. Chile

Memorista Escuela de Geografía, Portugal 084, Santiago, R.M. Chile
} 


\section{INTRODUCCIÓN}

Desde el punto de vista histórico, las interacciones espaciales entre el río Mapocho y la ciudad de Santiago, en constante expansión, son parte de los escenarios problemáticos que ha debido enfrentar la urbe en su avance sobre los sectores riparianos y el cauce mismo de este eje fluvial. El proceso de expansión a expensas del territorio fluvial ha significado, entre otros procesos: eliminar uno de los brazos del río; enfrentar sus no menos frecuentes salidas del cauce madre o desbordes; diseñar y construir obras paliativas (Tajamares del Mapocho); estrechamiento del cauce en algunas secciones; abovedamiento del cauce intraurbano mediante mampostería de piedra; nuevos desmadres ante crecidas (ej.: 1997); aplicación de gaviones; usurpación de sus riberas con concesiones viales, etc., ello sin mencionar los aspectos relativos a la sanidad de sus aguas.

Dada esta situación respecto del río en su tramo urbano y la abundancia de superficies duras en sus franjas ribereñas, en detrimento de los corredores verdes recomendados desde inicios de la segunda mitad del siglo pasado $^{4}$, se ha planteado recientemente retomar esta idea y proponer nuevamente la interconexión de los parques del río Mapocho intra-urbano. Ello, sin embargo, se ve poco factible dada la tendencia seguida por el crecimiento urbano y vial en las últimas décadas. En este contexto, este proyecto tiene como propósito adelantarse a la invasión urbana sobre aquel tramo del río Mapocho comprendido entre las comunas de Pudahuel y El Monte, donde, excepción hecha de algunos centros urbanos menores, aún quedan importantes secciones de cauce y zonas riparianas con escasa a moderada

4 En el año 1959 Mario Pérez de Arce ya planteaba aprovechar las riberas del Mapocho para $32 \mathrm{~km}$ de parques interconectados desde Barnechea a Pudahuel. intervención urbana, predominando los usos agrícolas y las parcelaciones de agrado.

Como una respuesta a la potencial expansión urbana hacia dichas comunas del poniente y sur poniente de Santiago, y resultado de las presiones ejercidas por los grupos inmobiliarios, se están desarrollando los procesos conducentes a decretos de cambios de uso del suelo de rural a urbano. Considerando que el corredor fluvial del río Mapocho en su sección inferior se encuentra bajo la ávida mirada de los inversionistas y empresas constructoras, esta investigación se orienta a evaluar el sistema físico ambiental del territorio fluvial del Mapocho inferior, y a establecer criterios que, desde el punto de vista geográfico y ambiental, pueden servir para orientar las intervenciones urbanísticas.

En consecuencia, los objetivos de esta investigación son, analizar las componentes geográfico-físicas, estáticas y dinámicas, del territorio fluvial correspondiente a la sección inferior del río Mapocho; caracterizar tanto la calidad como la fragilidad de las unidades geomorfológicopaisajísticas diferenciadas y establecer una propuesta de usos recomendados bajo la óptica de la valoración ecológico-ambiental del territorio fluvial.

\section{Área de Estudio}

Dentro de la sección inferior del río Mapocho, se planteó como área de estudio el sector del cauce y sus riberas comprendidas entre el límite occidental de la Comuna de Quinta Normal por el N, y la localidad de El Monte por el S. Por el E se adopta como límite la Autopista del Sol y por el W la línea de cumbres del cordón de cerros divisorio con la cuenca del Estero Puangue (Fig. 1).

El curso inferior del río Mapocho hasta su confluencia con el río Maipo, desarrolla la primera sección de su cauce con dirección NNE-SSW entre depósitos aluviales corres- 
pondientes a la sección distal del cono de deyecciones construido por sí mismo, así como disectando los depósitos de cenizas volcánicas conocidos como Pumicitas de Pudahuel.

La segunda sección se orienta en forma aproximada de $\mathrm{N}$ a $\mathrm{S}$ y transita por la franja de contacto entre los grandes conos de deyección edificados por el propio Río Mapocho como por el río Maipo con los conos aluviales menores, rellenos de rinconadas y extremos de las ramificaciones orientales de los relieves de la Cordillera de la Costa.

\section{MATERIALES Y MÉTODOS}

La metodología se basó, en una primera etapa, en un reconocimiento de los aspectos geomorfológicos, para lo cual se estudió los antecedentes que describen por separado las características constitutivas y dinámicas del medio físico. En una segunda etapa, y considerando que el medio se hace paisaje cuando alguien lo percibe (GÓMEZ OREA 1994), los elementos geomorfológicos fueron utilizados como un criterio relevante a la hora de generar un análisis en cuanto a la calidad paisajística en términos de clasificación y valoración. Sobre esta base se establecen sectores con diferente valor ambiental y potencialidades de uso, lo que se efectúa mediante el proceso de generación de matrices de calidad y de fragilidad según el modelo de CENTENO et al. (1994). De estos resultados y de los considerandos empleados, se establecen recomendaciones específicas visualizando una relación socio-natural armónica.

En concordancia con lo señalado y basados en lo planteado en el modelo indicado, el área de estudio es sometida a procedimientos metodológicos y análisis, mediante los cuales se establece para cada unidad geomorfológica calificaciones y peso según las siguientes variables: el relieve y su complejidad, el desnivel, la vegetación, presencia de masas de agua, accesibilidad, incidencia visual, y acciones antrópicas.

Dentro de estos procedimientos se analizan las características topográficas, las geomorfológicas y la relación entre procesos y formas resultantes dada la dinámica que registra el sistema natural. Respecto de este último aspecto, se dice que cuando la magnitud es mayor, los procesos controlan las formas y, al revés, cuando la magnitud es menor, las formas controlan los procesos (GRAF 1988). En consecuencia, un canal fluvial es un elemento geomorfológico cuya forma y dimensión están supeditadas a su función, pero más aún, a la dinámica y energía de los procesos que en él ocurren. Pues bien, el Río Mapocho sufre de ambos extremos, ya que su comportamiento no es ponderado y menos regular. Cambia aleatoriamente de estero a torrente, de 10 m3/s a 700 m3/s. Dada esta característica, es claro que el Río Mapocho ejerce un fuerte control sobre las formas y paisaje circundante, es decir, sobre su territorio. 


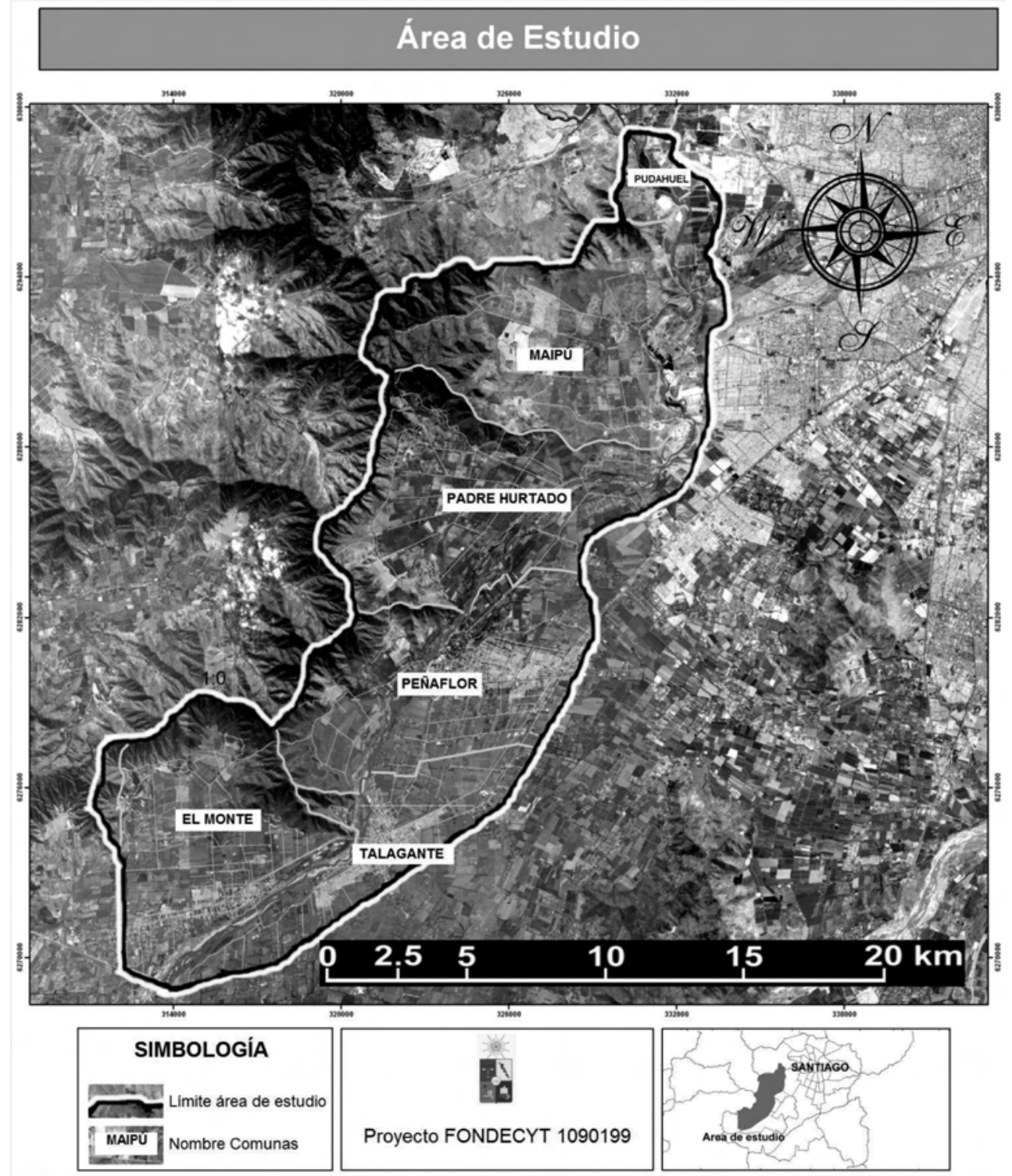

Fig. 1. Área de estudio.

Considerando estos antecedentes, y en base a fórmulas y pesos relativos de un conjunto de variables preestablecidas se determinó la calidad y fragilidaddeestasunidadesespaciales, de cuya relación ponderada se estableció la calidad paisajística de unidades espaciales diferenciadas hidrogeomorfológicamente.
En este sentido, y conforme a la metodología de CENTENO et al. (1994), la calidad corresponde al valor intrínseco de un paisaje desde el punto de vista visual, y la fragilidad se concibió como el riesgo de deterioro del mismo a consecuencia de la implantación de actividades humanas. 
Los parámetros que este modelo consideró para la determinación de la calidad (Vc) y la fragilidad (Vf) del paisaje son:

- Complejidad topográfica y relieve

- Desnivel (de las franjas riparianas) respecto eje fluvial

- Vegetación y usos agrícolas del suelo (terrazas adyacentes)

- Presencia de masas de agua (Pozos lastre $=>$ Lagunas)

- Actuaciones humanas (instalaciones)

- Grado de accesibilidad (Vialidad propiedad privada)

- Incidencia visual (calidad del paisaje)

Determinados ambos parámetros, estos son relacionados según lo establecido por el modelo para determinar la calidad total del paisaje, lo que se expresa finalmente en una matriz.

Para establecer el Valor de la Calidad Total del Paisaje (Cp) de cada unidad geomorfológica se realizó la sumatoria de los productos de los pesos absolutos y relativos de cada parámetro. Luego se integraron para establecer el valor total de cada unidad según la relación:

$$
\mathrm{Cp}=(2 \mathrm{Vc}+\mathrm{Vf}) / 3
$$

Complementariamente, y considerando tanto la existencia de elementos diferenciantes al interior de cada unidad geomorfológicopaisajística como la relevancia de otras componentes del medio, se desarrolló un proceso de análisis en base a antecedentes disponibles tales como geología, sedimentología, suelos, movimientos en masa, erosión, permeabilidad, y antropización. Esto se efectuó desde un punto de vista cualitativo, lo que permitió finalmente determinar la espacialidad integrada de cada unidad de paisaje, y facilitar el establecimiento de las recomendaciones de uso en base a criterio experto.

\section{Antecedentes teóricos}

En su crecimiento, Santiago se ha estado transformando en una ciudad con predominio de superficies duras, especialmente en las comunas del centrooeste. A la fecha, desde el punto de vista de las áreas verdes, el promedio indica que cuenta con sólo 4,7 metros cuadrados por habitante, lo cual corresponde a la mitad de lo recomendado por la Organización Mundial de la Salud.

Al respecto, VÁSQUEZ (2009) ha planteado la necesaria incorporación del criterio de sostenibilidad desde la perspectiva ecológica en la planificación urbana de los territorios, especialmente los metropolitanos. En este sentido ha señalado como uno de los orígenes del problema la falta de conciencia de la finitud de los recursos, y el hecho que en términos de propiedad del territorio, nosotros pertenecemos a él y no al revés, por lo que se deben buscar los mecanismos para poner freno a lo que denomina "orgía inmobiliaria".

Por otra parte, desde el punto de vista de la interacción entre hidro-morfodinámica y ecología, y de acuerdo con los conceptos de flood pulse (JUNK et al. 1989) y flow pulse (TOCKNER et al. 2000), es evidente que las pulsaciones, ritmos o fluctuaciones de caudal regulan los intercambios ecológicos entre las distintas unidades acuáticas y terrestres del sistema y, por tanto, son fundamentales para la supervivencia de los corredores ribereños adyacentes a los cauces. Esta es la base de la conectividad ecológica lateral o transversal, lo que viene a complementar las relaciones de este tipo que se desarrollan en sentido longitudinal.

Así, las crecidas y las altas aguas estacionales incrementan la dinámica de todas las interacciones, ya que conectan el cauce principal con los brazos muertos y con el corredor ribereño, recuperándose las conexiones interrumpidas en condiciones de bajas aguas. Este funcionamiento por 
pulsaciones de los ecosistemas fluviales y ribereños constituye un criterio básico para la gestión hídrica de ríos, siendo visto como crecida ecológica (OLLERO \& ROMEO 2007) por su efecto en el ecosistema, su espacialidad y funcionamiento.

Bajo estas conceptualizaciones, los corredores fluviales pueden ser valorizados como un recurso natural en la medida que se consideren los distintos servicios ambientales y ecológicos que proveen, tanto al medio ambiente construido como al medio ambiente natural.

Entre las funciones ambientales de los corredores fluviales, en tanto criterios aplicables al Ordenamiento territorial, cabe destacar las siguientes (FERRANDO 2010):

- Servir de zona de seguridad y mitigación de eventos hidrológicos extremos.

- Cumplir funciones de Corredor Biológico.

- Servir como parque recreacional y deportivo.

- Constituir una franja de aireación urbana.

- Cumplir funciones de regulación del clima urbano.

- Mejorar el paisaje urbano.

- Cumplir funciones culturales y sociales.

- Mejorar la calidad de vida de los habitantes.

Por otra parte, para contar con ríos vivos, es decir, para conservar su biocenosis, hay que proteger su dinámica (OLLERO 2003). En este sentido, ante intervenciones, los mejores restauradores de la dinámica fluvial son los propios sistemas fluviales, y el río Mapocho lo ha demostrado en sus eventos históricos. Los ríos tienen tendencia a reconstruir su geomorfología, a autocorregirse, a readaptarse a los factores físicos, siempre que se eliminen los elementos antrópicos que los perturban (WILLIAMS et al. 2001), labor que los mismos ríos se pueden encargar de llevar a cabo. Es lo que se puede llamar resiliencia fluvial.

Si bien se puede afirmar que mientras la cantidad de caudal circulante, la distribución temporal y los procesos extremos, respondan a la dinámica natural, el sistema fluvial cumplirá perfectamente su función de transporte hidrológico y mantendrá morfologías acordes con ese funcionamiento. También es factible, y la mayoría de las veces necesario, intervenir adecuadamente el sistema para establecer ordenamientos y controles con el objeto de mitigar los procesos hidromorfológicos y reducir los impactos negativos tanto sobre el medioambiente natural como sobre el construido.

Sin embargo, debe tenerse en cuenta que toda reducción de la funcionalidad natural y de los espacios requeridos para su desarrollo tiene como consecuencia el incremento del nivel de amenaza del sistema fluvial, ya sea aguas abajo de la intervención, o en la margen opuesta. Ello requiere considerar esta dinámica natural en el proceso de ordenamiento territorial para asegurar la sostenibilidad del desarrollo.

Refrendando lo señalado, se considera que la pérdida de naturalidad en el trazado de un cauce es una pérdida de patrimonio natural y de geo-diversidad, poniéndose en peligro la dinámica fluvial y el buen estado ecológico (OLLERO \& ROMEO 2007).

\section{RESULTADOS}

En el contexto de lo planteado por VÁSQUEZ (2009), si ya poco se puede hacer por las riberas del Mapocho intra-urbano, aún se está a tiempo de poder hacer algo para establecer y posicionar en las autoridades los criterios adecuados para, junto con rescatar los servicios ambientales que provee su curso inferior, impulsar un ordenamiento territorial que incorpore adecuadamente la dinámica de los sistemas naturales y cautele las funciones ecológicas de este corredor fluvial. 
En este sentido, el territorio fluvial en estudio debe ser entendido como un espacio sistémico que incluye el cauce, las riberas y los terrenos adyacentes (zonas riparianas), cuyo límite externo es establecido por la propia dinámica de las aguas y la movilidad lateral del mismo. Por lo tanto incluye el lecho episódico y también los brazos abandonados más recientes, los cuales presentan una condición de humedal.

Desde esta dimensión, el río Mapocho trasciende lo local, incluso lo regional, ejerciendo un rol de interconector ecológico, tanto en lo longitudinal (como se aprecia en la figura 2) como en lo transversal. Al respecto, y de acuerdo con OLLERO \& ROMEO (2007), los ríos son sistemas naturales enormemente dinámicos y complejos. Concordantemente, además de su principal función, que es el transporte de agua, sedimentos, nutrientes y seres vivos, y sus variaciones espaciotemporales, también conforman corredores de gran valor ecológico, paisajístico, bioclimático y territorial, que enlazan montañas y tierras bajas. Por tanto, la red fluvial constituye un elemento clave en la dinámica ambiental y en la planificación territorial.

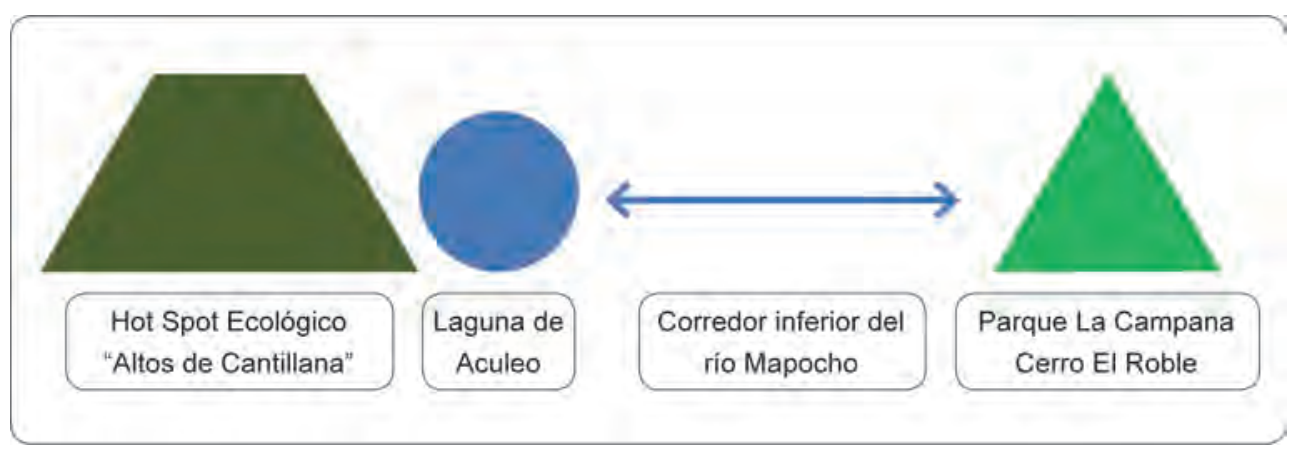

Fig. 2: Río Mapocho inferior como interconector ecológico.

En el caso específico de este estudio, el río Mapocho inferior constituye un sistema complejo y dinámico y, a la vez, un paisaje activo, que es mucho más que lo que sucede entre la mirada y el horizonte. Son múltiples los procesos en él y asociados a él, tanto de origen natural como producto de la intervención humana, que están ocurriendo y modificando continuamente su territorio fluvial.

En este contexto, cada unidad geomorfológica fue valorada según los parámetros establecidos en el método adoptado (ver metodología) en cuanto a calidad del paisaje $(\mathrm{Vc})$ y fragilidad del paisaje (Vf) en categorías de 1 (baja) a 5 (alta). El procedimiento permitió elaborar la matriz de calidad total del paisaje (tabla 1).

Complementariamente, y como una forma de alcanzar mejores resultados y recomendaciones más ajustadas a la realidad, se procedió al análisis de cada unidad geomorfológica según los criterios considerados en la metodología (características de ciertas componentes físicas y humanas), lo que permitió determinar la mantención o subdivisión de algunas de las unidades geomorfológicas y mejorar su caracterización. 
Tabla i: Calidad Total del Paisaje

\begin{tabular}{|c|c|c|c|c|c|c|c|c|c|c|}
\hline 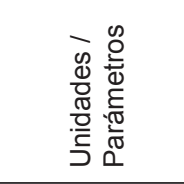 & 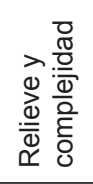 & 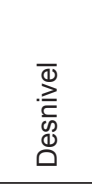 & 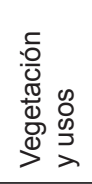 & 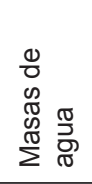 & 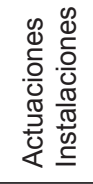 & 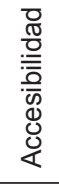 & 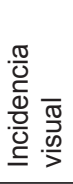 & $\frac{i}{i 0}$ & 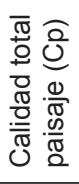 & $\begin{array}{l}\frac{\pi}{2} \\
\frac{0}{0} \\
\frac{d}{0} \\
0\end{array}$ \\
\hline $\begin{array}{l}\text { Cono } \\
\text { Mapocho }\end{array}$ & $1 \times 3 / 3 \times 5$ & $1 \times 1 / 1 \times 5$ & $1 \times 2 / 2 \times 1$ & $3 \times 1 / 2 \times 3$ & $5 \times 2 / 1 \times 5$ & $2 \times 3$ & $3 \times 3$ & & 2.54 & 2 \\
\hline Cono Maipo & $1 \times 3 / 3 \times 5$ & $4 \times 1 / 1 \times 2$ & $1 \times 2 / 2 \times 1$ & $3 \times 1 / 2 \times 3$ & $2 \times 2$ & $2 \times 5$ & $3 \times 3$ & & 2.27 & 1 \\
\hline $\begin{array}{l}\text { Flanco de } \\
\text { Valle activo }\end{array}$ & $4 \times 3 / 3 \times 2$ & $5 \times 1 / 1 \times 1$ & $3 \times 2 / 2 \times 4$ & $1 \times 1 / 2 \times 1$ & $5 \times 2 / 1 \times 5$ & $2 \times 4$ & $3 \times 5$ & & 3.58 & 5 \\
\hline $\begin{array}{l}\text { Flanco de } \\
\text { valle pasivo }\end{array}$ & $4 \times 3 / 3 \times 2$ & $5 \times 1 / 1 \times 1$ & $5 \times 2 / 2 \times 5$ & $1 \times 1 / 2 \times 1$ & & $2 \times 2$ & $3 \times 5$ & & 3.32 & 4 \\
\hline $\begin{array}{l}\text { Cono } \\
\text { torrencial } \\
\text { indiferenciado }\end{array}$ & $5 \times 3 / 3 \times 4$ & $3 \times 1 / 1 \times 3$ & $3 \times 2 / 2 \times 4$ & $1 \times 1 / 2 \times 3$ & $5 \times 2 / 1 \times 5$ & $2 \times 1$ & $3 \times 5$ & & 3.80 & 5 \\
\hline $\begin{array}{l}\text { Cono } \\
\text { torrencial de } \\
\text { rinconada }\end{array}$ & $2 \times 3 / 3 \times 4$ & $3 \times 1 / 1 \times 3$ & $2 \times 2 / 2 \times 2$ & $3 \times 1 / 2 \times 3$ & $4 \times 2 / 1 \times 4$ & $2 \times 1$ & $3 \times 1$ & & 2.58 & 2 \\
\hline $\begin{array}{l}\text { Terraza } \\
\text { Mapocho }\end{array}$ & $1 \times 3 / 3 \times 5$ & $1 \times 1 / 1 \times 5$ & $1 \times 2 / 2 \times 1$ & $3 \times 1 / 2 \times 3$ & $5 \times 2 / 1 \times 5$ & $2 \times 1$ & $3 \times 3$ & & 2.45 & 1 \\
\hline $\begin{array}{l}\text { Terraza } \\
\text { cineritas }\end{array}$ & $2 \times 3 / 3 \times 4$ & $1 \times 1 / 1 \times 5$ & $2 \times 2 / 2 \times 2$ & $3 \times 1 / 2 \times 3$ & $5 \times 2 / 1 \times 5$ & $2 \times 5$ & $3 \times 3$ & $2.66 / 2.92$ & 2.75 & 3 \\
\hline
\end{tabular}

En base a estos resultados se construyó la siguiente tabla resumen (Tabla 2), la cual indica la calidad integrada del paisaje respecto de cada unidad o subunidad geomorfológica establecida. La espacialidad de cada unidad o subunidad geomorfológica, diferenciadas según el procedimiento que llevó a establecer su calidad paisajística integrada se expresa en la siguiente cartografía (Fig. 3).

Posteriormente, considerando las categorías de unidades de paisaje establecidas en el modelo utilizado y las recomendaciones generales planteadas en este, sumado ello al conocimiento empírico y a los resultados del reconocimiento directo, se procedió a asignar a cada unidad geomorfológicopaisajística las alternativas de uso y las aptitudes o restricciones que se desprenden de su caracterización, distinguiéndose zonas aptas para preservación-recuperación, restricción por riesgo diverso, ecoturismo, deportes, parques inundables, áreas de picnic y recreación, áreas de uso industrial, sectores aptos para urbanización de baja densidad y de densidad media, y sectores apropiados para comercio y vialidad estructurante. 


\begin{tabular}{|c|c|c|c|c|c|}
\hline 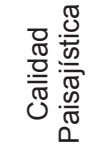 & 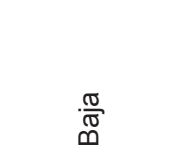 & $\begin{array}{l}\frac{\pi}{\pi} \\
\infty \\
\stackrel{0}{\pi} \\
\sum\end{array}$ & $\begin{array}{l}\frac{\pi}{0} \\
\frac{\pi}{0} \\
\frac{\pi}{2} \\
\sum\end{array}$ & $\begin{array}{l}\frac{\pi}{0} \\
\frac{\pi}{0} \\
\frac{\pi}{0} \\
\frac{0}{2}\end{array}$ & $\begin{array}{l}\frac{\pi}{\pi} \\
\infty \\
\stackrel{0}{\pi} \\
\sum\end{array}$ \\
\hline 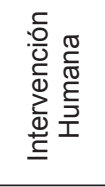 & 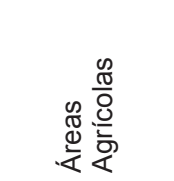 & 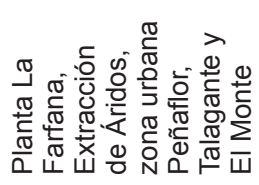 & 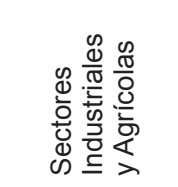 & 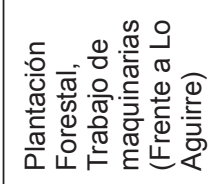 & 悉 \\
\hline 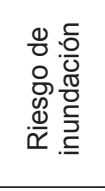 & $\stackrel{\circ}{\frac{\pi}{\pi}}$ & 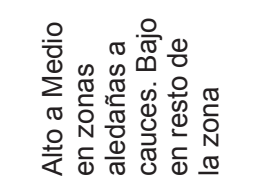 & $\begin{array}{l}.0 \\
\frac{0}{\pi} \\
\pi \\
\pi \\
.0 \\
\frac{0}{0} \\
\sum\end{array}$ & $\begin{array}{l}\stackrel{0}{\pi} \\
\infty \\
\pi \\
\stackrel{0}{0} \\
\frac{0}{0} \\
\frac{0}{2}\end{array}$ & $\frac{9}{\frac{2}{<}}$ \\
\hline 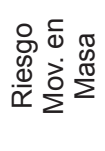 & 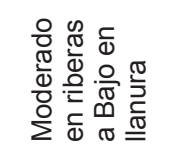 & 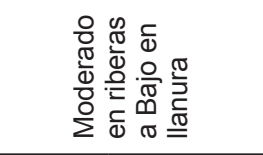 & $\stackrel{\circ}{\frac{0}{\mathscr{D}}}$ & $\stackrel{\circ}{\stackrel{\otimes}{\mathbb{D}}}$ & 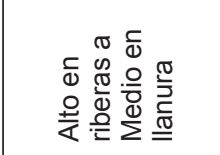 \\
\hline 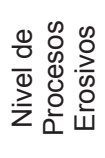 & 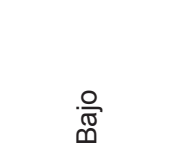 & 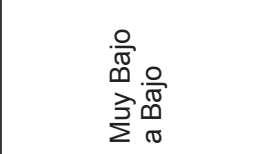 & 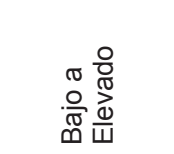 & $\begin{array}{l}\frac{0}{0} \\
\frac{\pi}{0} \\
\frac{0}{0} \\
\frac{0}{2}\end{array}$ & $\begin{array}{l}\frac{0}{0} \\
\frac{\pi}{\pi} \\
\frac{0}{0} \\
\frac{0}{2}\end{array}$ \\
\hline 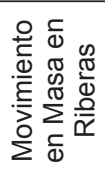 & $\bar{\omega}$ & $\bar{\omega}$ & $\bar{\omega}$ & $\bar{s}$ & $\bar{s}$ \\
\hline 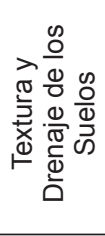 & 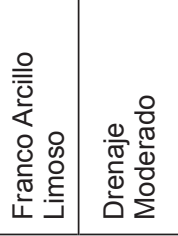 & 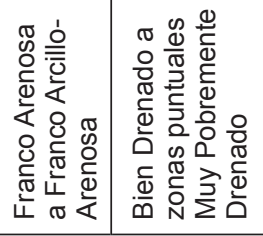 & 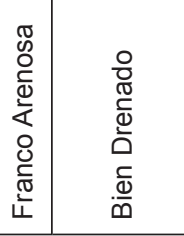 & 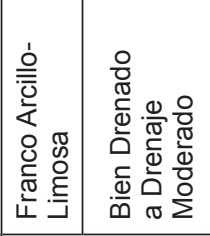 & 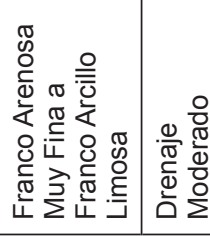 \\
\hline 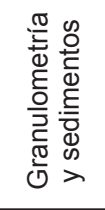 & 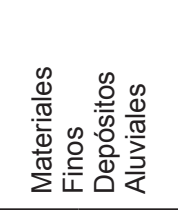 & 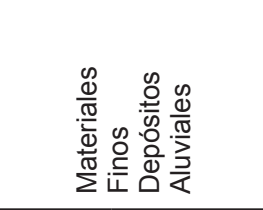 & 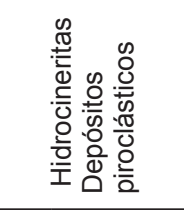 & 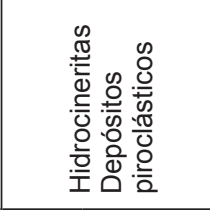 & 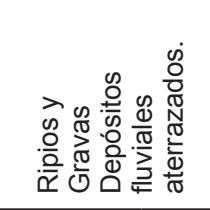 \\
\hline 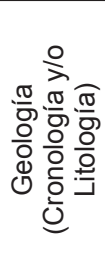 & 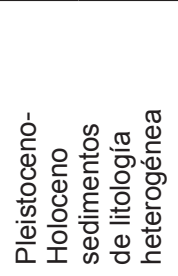 & 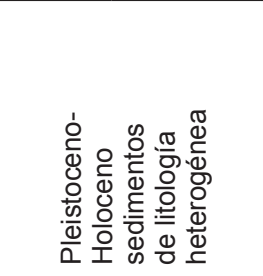 & 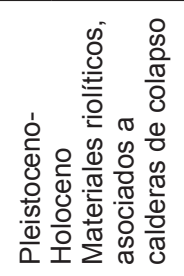 & 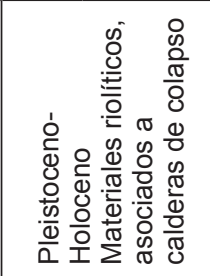 & 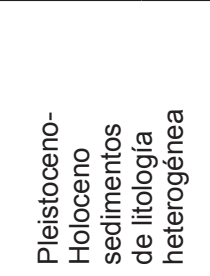 \\
\hline 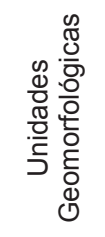 & $\begin{array}{l}\frac{0}{0} \\
\frac{0}{0} \\
\frac{2}{\pi} \\
\sum_{2} \\
0 \\
0 \\
0\end{array}$ & 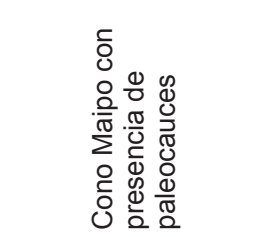 & 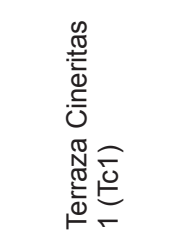 & 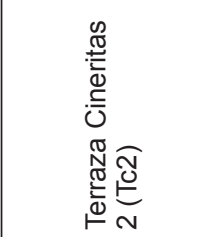 & 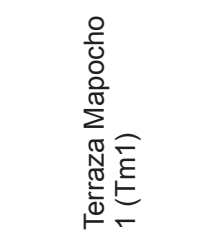 \\
\hline
\end{tabular}




\begin{tabular}{|c|c|c|c|c|c|c|}
\hline 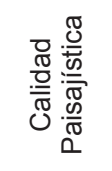 & $\begin{array}{l}\frac{\pi}{\pi} \\
\infty \\
3 \\
\sum\end{array}$ & $\begin{array}{l}\frac{\pi}{\pi} \\
\infty \\
\frac{\pi}{\pi} \\
\sum\end{array}$ & 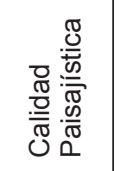 & $\begin{array}{l}\frac{\pi}{\pi} \\
\infty \\
\frac{\pi}{2} \\
\sum\end{array}$ & $\begin{array}{l}\frac{\pi}{\pi} \\
\infty \\
\frac{\pi}{2} \\
\sum\end{array}$ & $\begin{array}{l}\frac{\pi}{\sqrt{\pi}} \\
\infty \\
\frac{\infty}{2}\end{array}$ \\
\hline 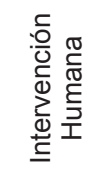 & 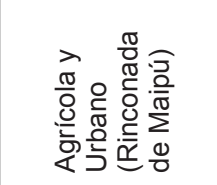 & 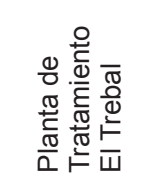 & 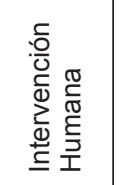 & 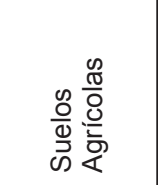 & 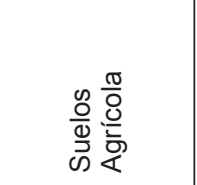 & 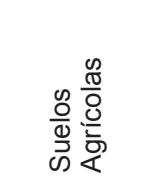 \\
\hline 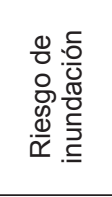 & $\frac{9}{<}$ & $\begin{array}{l}\frac{0}{\pi} \\
\infty \\
\pi \\
\circ \\
\frac{0}{0} \\
\sum \\
\end{array}$ & 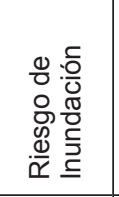 & $\begin{array}{l}\frac{0}{\pi} \\
\sum_{\pi}^{\infty} \\
\pi \\
\stackrel{0}{\pi} \\
\infty\end{array}$ & $\begin{array}{l}\frac{0}{0} \\
\sum_{\pi}^{0} \\
\pi \\
\stackrel{0}{\pi} \\
\infty\end{array}$ & $\begin{array}{l}\frac{0}{7} \\
\frac{0}{2} \\
\end{array}$ \\
\hline 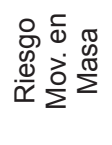 & 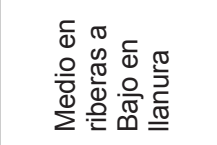 & 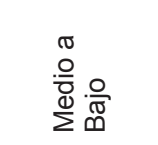 & 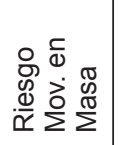 & $\begin{array}{l}\frac{0}{\overline{0}} \\
\sum^{0}\end{array}$ & 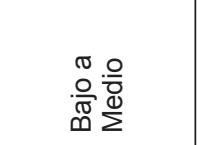 & $\frac{\text { 원 }}{2}$ \\
\hline 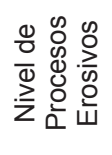 & $\begin{array}{l}\frac{0}{0} \\
\frac{\pi}{\frac{\pi}{0}} \cdot 0 \\
\frac{0}{0} \\
\sum \frac{\pi}{\pi} \\
\sum \pi\end{array}$ & $\stackrel{\circ}{\stackrel{\oplus}{\pi}}$ & 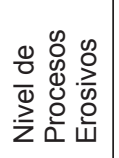 & 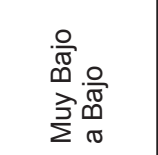 & 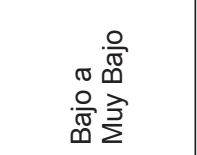 & 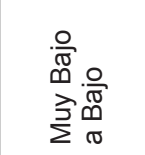 \\
\hline 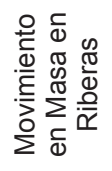 & ஸे & $\bar{\omega}$ & 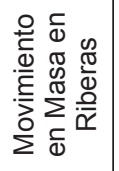 & ஸ & ஸे & ๘ \\
\hline 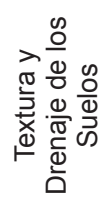 & 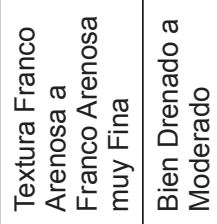 & 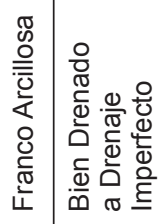 & 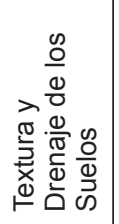 & 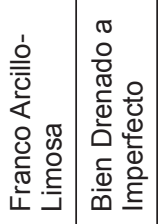 & 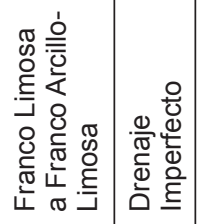 & 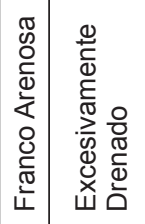 \\
\hline 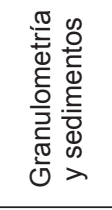 & 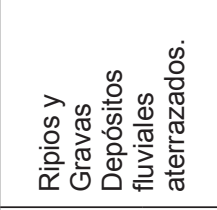 & 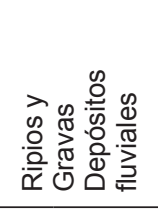 & 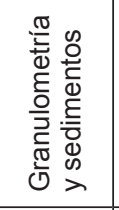 & 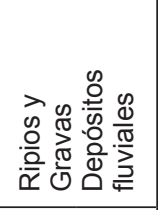 & 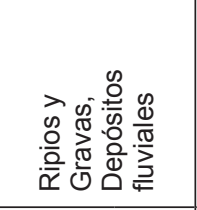 & 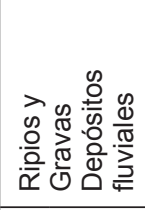 \\
\hline 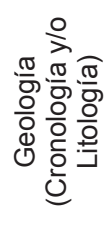 & 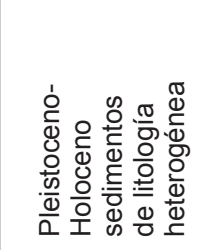 & 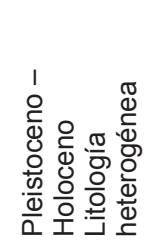 & 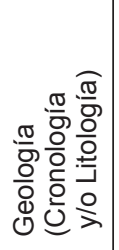 & 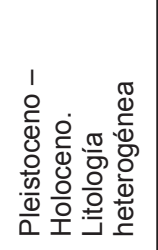 & 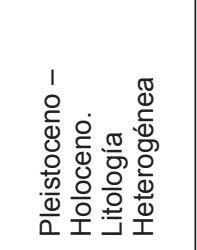 & 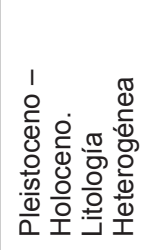 \\
\hline 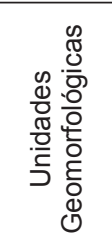 & 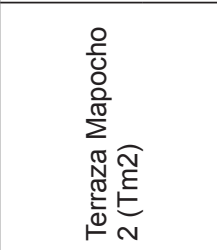 & 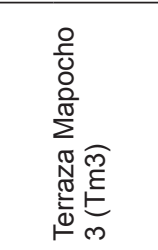 & 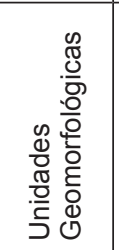 & 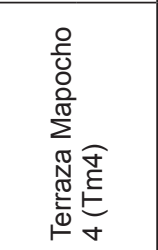 & 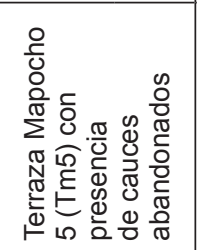 & 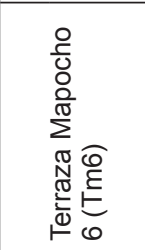 \\
\hline
\end{tabular}




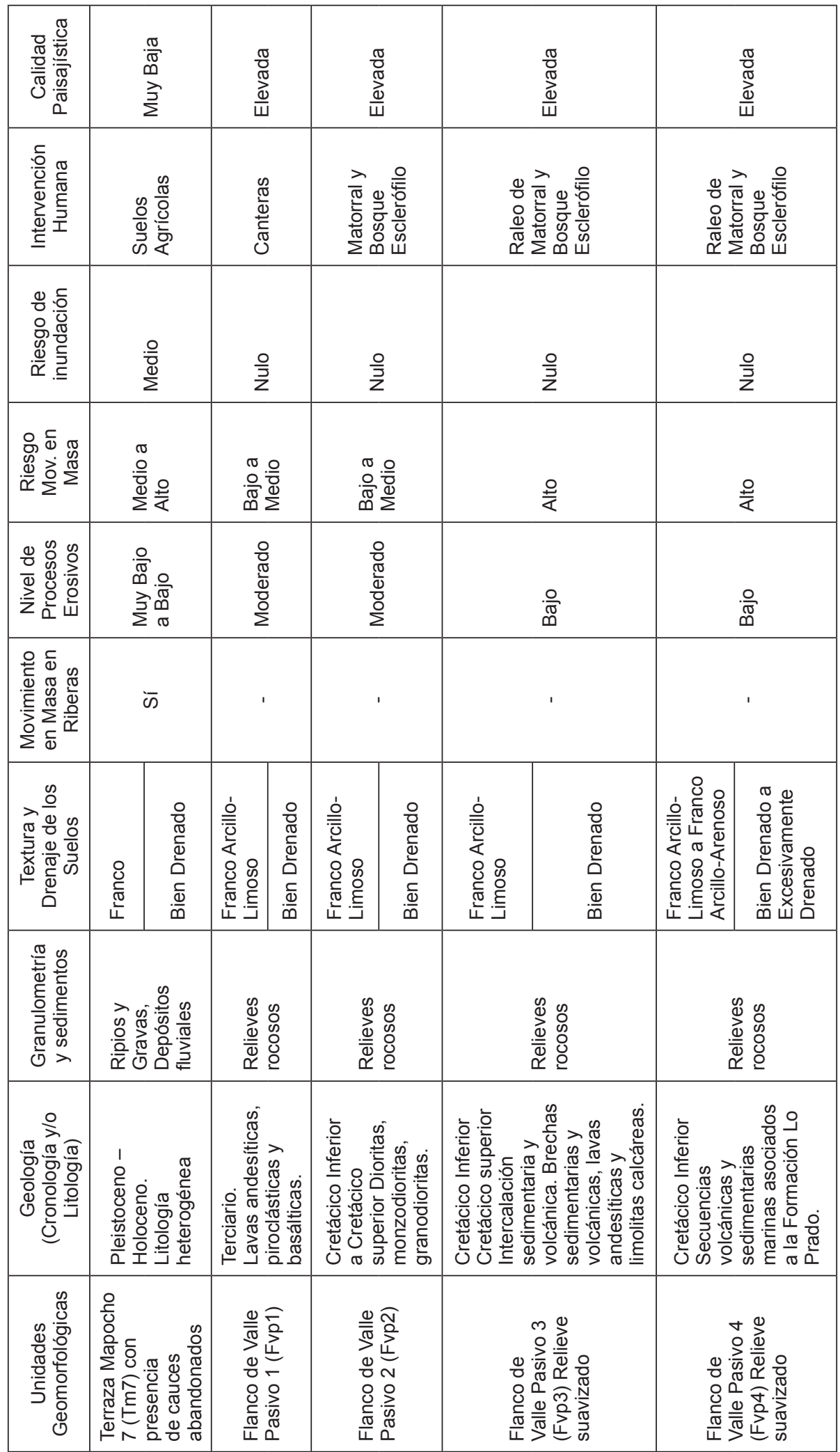




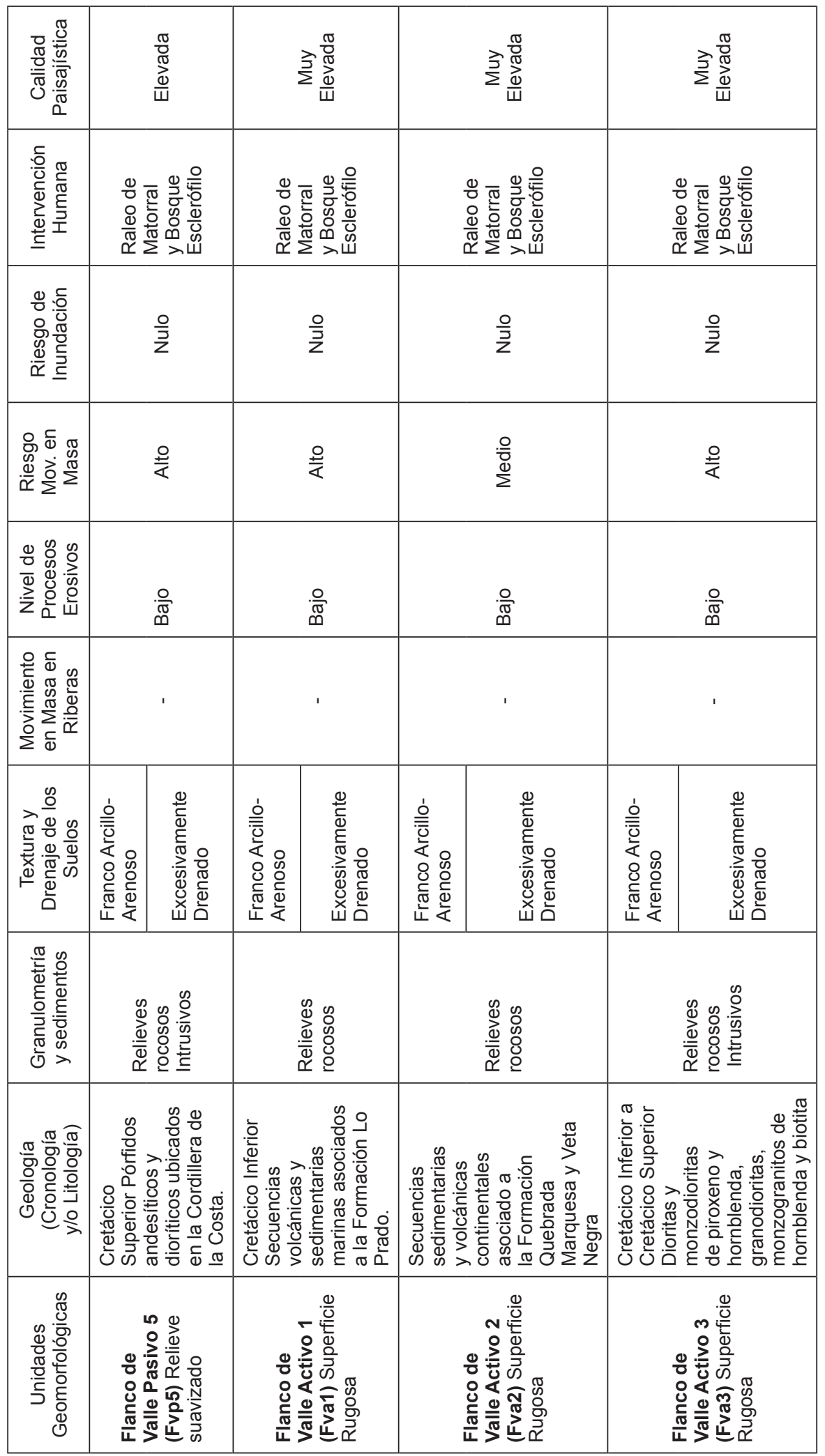




\begin{tabular}{|c|c|c|c|c|}
\hline 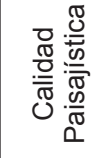 & $\stackrel{\frac{\pi}{\pi}}{\infty}$ & $\frac{\pi}{\pi}$ & $\sum^{3} \frac{\frac{\pi}{0}}{\frac{\pi}{0}} \frac{d}{w}$ & $\sum_{\frac{3}{2}}^{\frac{\pi}{0}} \frac{\pi}{\frac{\pi}{\omega}}$ \\
\hline 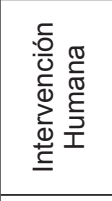 & 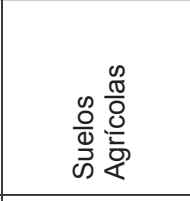 & 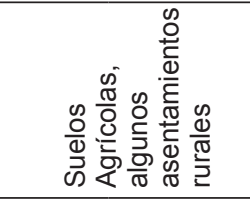 & 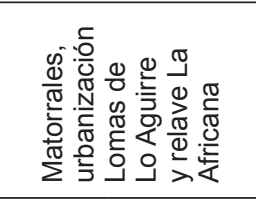 & 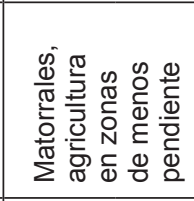 \\
\hline 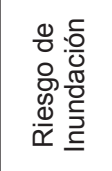 & 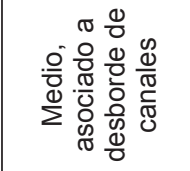 & 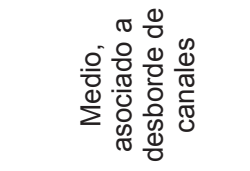 & $\begin{array}{l}\frac{0}{\overline{0}} \\
\frac{\mathbb{e}}{2}\end{array}$ & $\begin{array}{l}\frac{\text { 음 }}{0} \\
\frac{0}{2}\end{array}$ \\
\hline 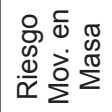 & $\stackrel{\circ}{\stackrel{\oplus}{\pi}}$ & 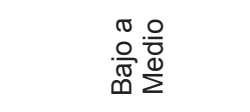 & $\begin{array}{l}\frac{\text { 응 }}{2} \\
\sum\end{array}$ & $\begin{array}{l}\frac{\text { 응 }}{2} \\
\frac{0}{2}\end{array}$ \\
\hline 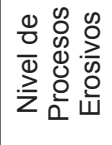 & $\begin{array}{l}\frac{0}{0} \frac{0}{\pi} \\
\frac{\pi}{\pi} \\
\frac{\pi}{0} \frac{\pi}{0} \\
\frac{0}{2} \\
\sum \pi \\
\Sigma\end{array}$ & 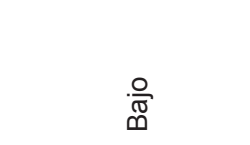 & $\begin{array}{l}\frac{0}{0} \\
\frac{\pi}{0} \\
\frac{\pi}{0} \\
\frac{0}{2}\end{array}$ & 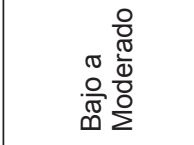 \\
\hline 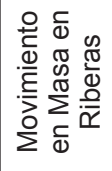 & ㅇ & ำ & 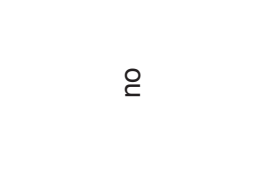 & ๕ \\
\hline 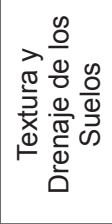 & 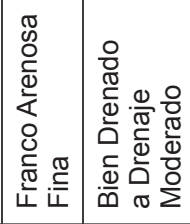 & 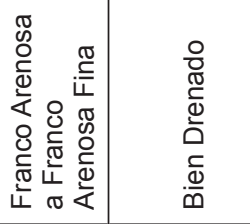 & 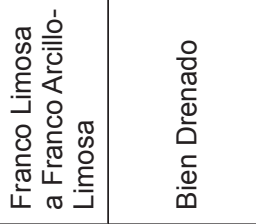 & 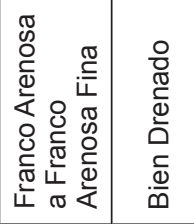 \\
\hline 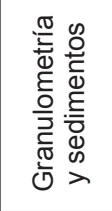 & 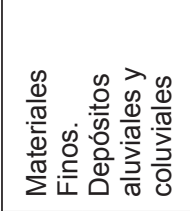 & 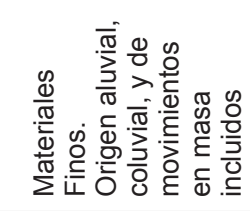 & 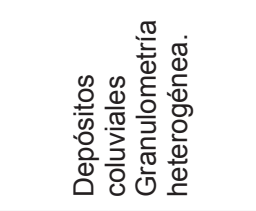 & 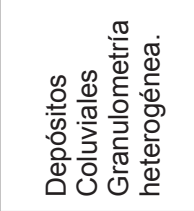 \\
\hline 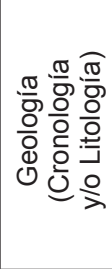 & 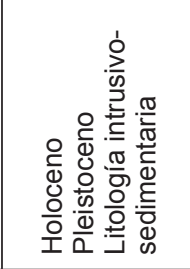 & 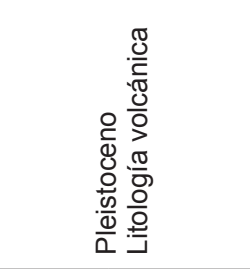 & 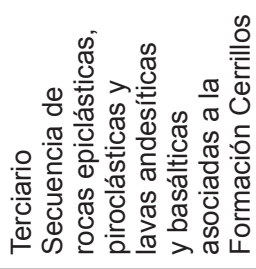 & 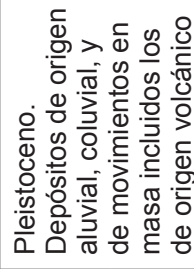 \\
\hline 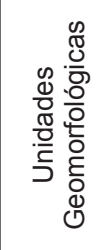 & 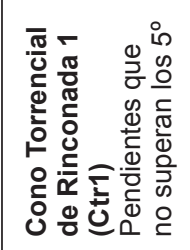 & 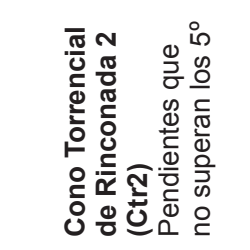 & 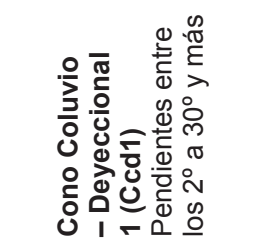 & 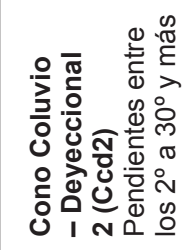 \\
\hline
\end{tabular}




\begin{tabular}{|c|c|c|c|}
\hline 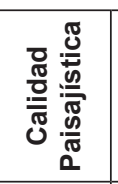 & $\sum_{\Sigma}^{3} \frac{\frac{\pi}{0}}{\frac{\pi}{\omega}}$ & $\sum_{\sum}^{3} \frac{\frac{\pi}{\pi}}{\frac{\pi}{\omega}}$ & $\sum_{\frac{3}{2}}^{\frac{\pi}{0}} \frac{\pi}{\omega}$ \\
\hline 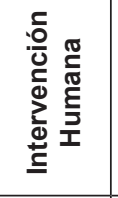 & 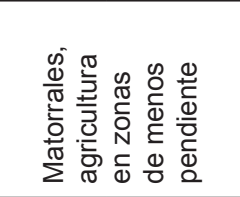 & 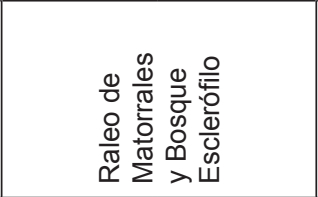 & 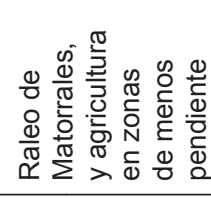 \\
\hline 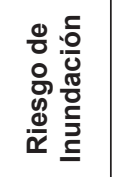 & $\frac{.0}{\frac{0}{0}}$ & $\stackrel{\circ}{\stackrel{\circ}{\mathbb{D}}}$ & $\frac{.0}{\frac{0}{0}}$ \\
\hline 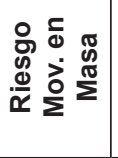 & $\begin{array}{l}\frac{.}{7} \\
\frac{\Phi}{2}\end{array}$ & $\begin{array}{l}0 \\
\stackrel{0}{0} \\
\frac{0}{2} \\
\sum\end{array}$ & 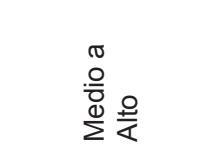 \\
\hline 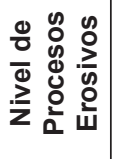 & $\begin{array}{l}\frac{0}{0} \\
\frac{\pi}{\pi} \\
\frac{\pi}{0} \\
\frac{0}{2}\end{array}$ & $\begin{array}{l}\frac{0}{\pi} \\
\frac{\pi}{0} \\
\frac{\pi}{0} \\
\Sigma \\
\Sigma\end{array}$ & 产 \\
\hline 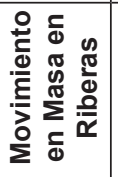 & 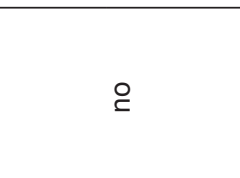 & ' & 1 \\
\hline 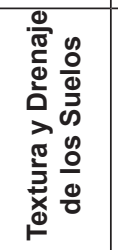 & 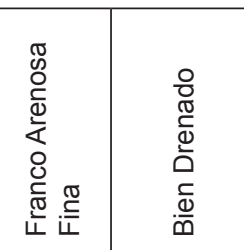 & 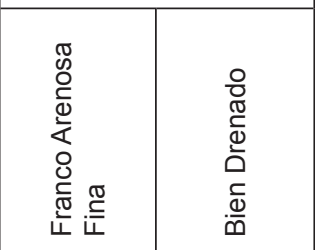 & 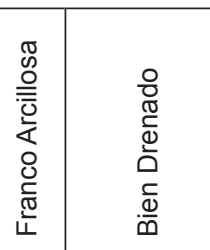 \\
\hline 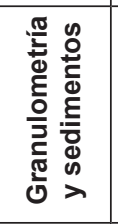 & 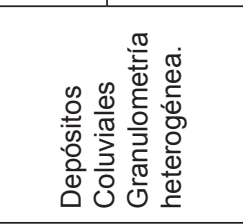 & 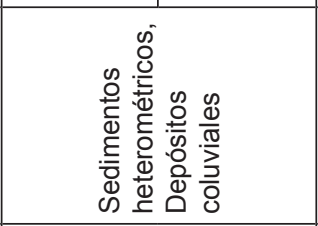 & 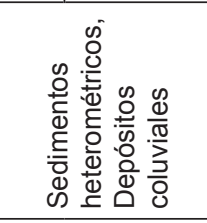 \\
\hline 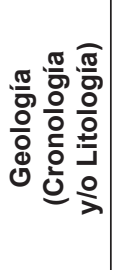 & 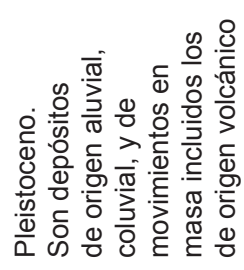 & 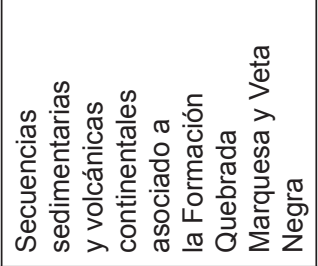 & 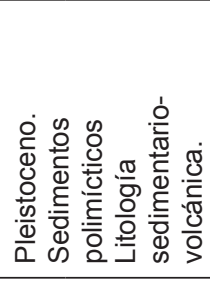 \\
\hline 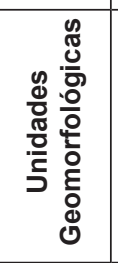 & 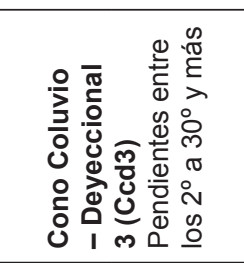 & 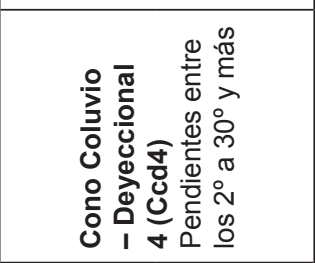 & 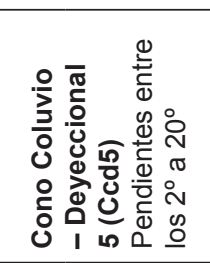 \\
\hline
\end{tabular}




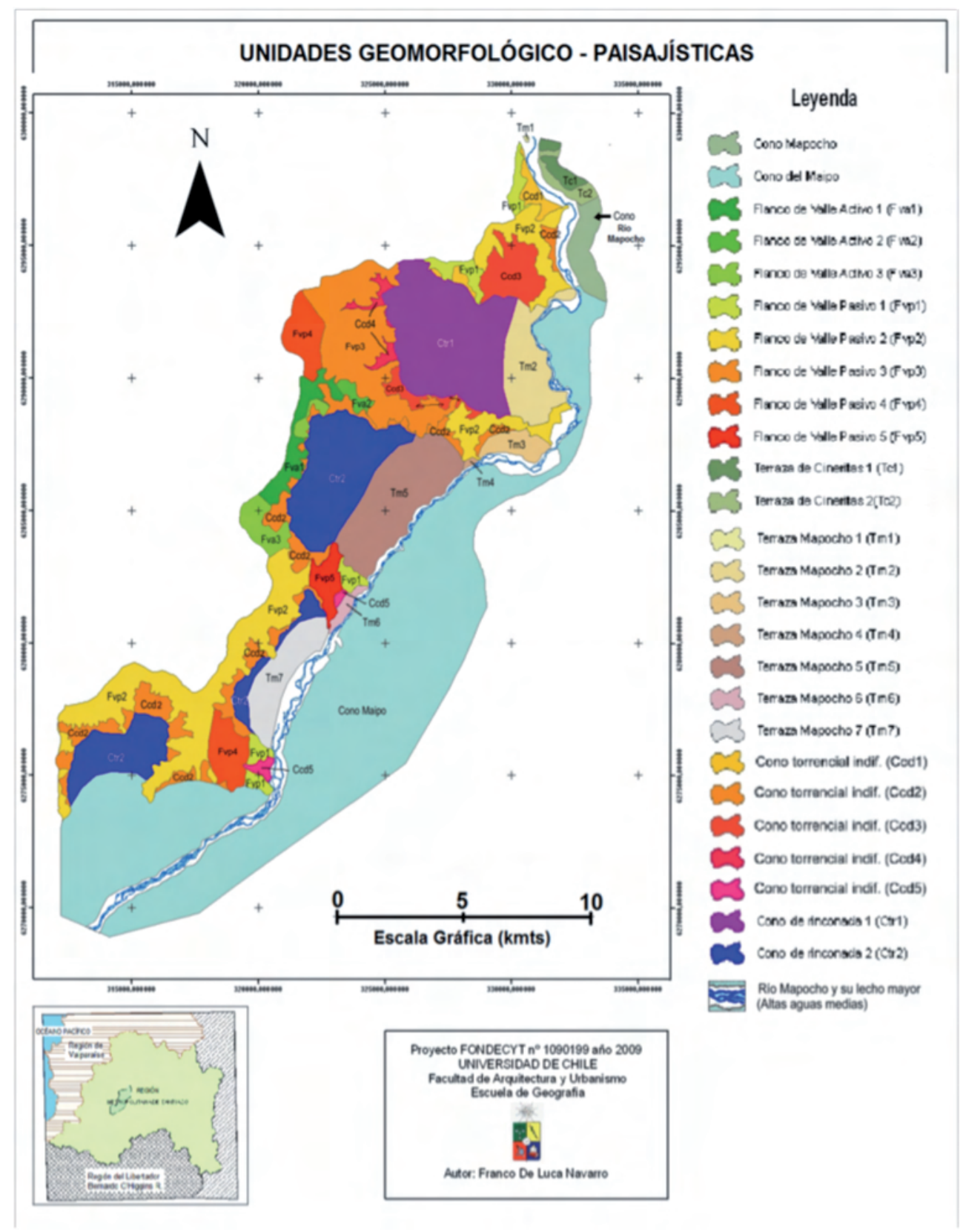

Fig. 3. Unidades Geomorfológico-Paisajísticas 
En este sentido, y en base a los resultados y al manejo de los antecedentes de la caracterización de las unidades, se establecieron las recomendaciones de uso que se indican a continuación (Tabla 3).

TABLA 3: Usos ReCOMENDAdos POR UNIDAd de PAISAJE

\begin{tabular}{|c|}
\hline Categoría 1 de Calidad del Paisaje \\
\hline Zona Ecoturismo, Turismo Aventura \\
\hline Actividades recomendadas \\
\hline Trekking, jogging, Observación de Naturaleza \\
\hline Aptitudes y/o Restricciones \\
\hline $\begin{array}{c}\text { Zonas de relieves apropiados para realizar actividades deportivas y establecer rutas-miradores para } \\
\text { apreciar la flora y la fauna, así como el paisaje en cuanto a su configuración topográfica. Se requie- } \\
\text { re la instalación de señalética que advierta sobre el cuidado al medioambiente y la no circulación } \\
\text { fuera de los senderos. }\end{array}$ \\
\hline
\end{tabular}

\begin{tabular}{|c|}
\hline Categoría 2 de Calidad del Paisaje \\
\hline Zona Deportes Aéreos y Miradores \\
\hline Actividades recomendadas \\
\hline Alas Delta, Parapente, Observación \\
\hline Aptitudes y/o Restricciones \\
\hline $\begin{array}{c}\text { Áreas de cumbres de cerros amesetadas o amplias y de pendientes moderadas aptas para realizar } \\
\text { prácticas de despegue. En los alrededores no debe existir ningún tipo de cableado aéreo o } \\
\text { estructuras elevadas. }\end{array}$ \\
\hline
\end{tabular}

\begin{tabular}{|c|}
\hline Categoría 3 de Calidad del Paisaje \\
\hline Zona Urbanización de Baja Densidad \\
\hline Actividades recomendadas \\
\hline Parcelas de Agrado, condominios con variadas áreas verdes (>70\% de la superficie) en \\
coexistencia con actividades agrícolas \\
\hline Aptitudes y/o Restricciones \\
\hline $\begin{array}{c}\text { Zonas planas o de baja pendiente con condiciones apropiadas para el asentamiento humano o } \\
\text { actividades económicas (agrícolas). No deben presentar problemas asociados a riesgos de } \\
\text { movimientos en masa, inundación o afloramiento de aguas subterráneas (napas superficiales). }\end{array}$ \\
\hline
\end{tabular}




\begin{tabular}{|c|}
\hline Categoría 4 de Calidad del Paisaje \\
\hline Zona Parques Inundables por Desborde \\
\hline Actividades recomendadas \\
\hline Áreas verdes, deportivas y/o de paseabilidad, preparadas para acumulación y paso de aguas de \\
crecidas fluviales \\
\hline Aptitudes y/o Restricciones \\
\hline $\begin{array}{c}\text { Zonas asociadas al borde del cauce y a terrazas bajas, que según sea el caso, presenten riesgo } \\
\text { moderado a sufrir inundaciones, ya sea que se trate de cauces abandonados o de grandes crecidas } \\
\text { fluviales. Sectores no apropiados para asentamientos humanos densos o actividades económicas. }\end{array}$ \\
\hline
\end{tabular}

\begin{tabular}{|c|}
\hline Categoría 5 de Calidad del Paisaje \\
\hline Zona Parques \\
\hline Actividades recomendadas \\
\hline Recreación, Picnic, Juegos \\
\hline Aptitudes y/o Restricciones \\
\hline $\begin{array}{c}\text { Sectores de relieves llanos a moderados, con condiciones ambientales adecuadas para este tipo de } \\
\text { actividades (sombra, árboles y cubierta herbácea, agua). Deben estar demarcados y protegidos los } \\
\text { sectores asociados a escarpes rocosos o a bordes de terraplenamientos fluviales. }\end{array}$ \\
\hline
\end{tabular}

\begin{tabular}{|c|}
\hline Categoría 6 de Calidad del Paisaje \\
\hline Zona Recreación Ribereña y Fluvial \\
\hline Actividades recomendadas \\
\hline $\begin{array}{c}\text { Actividades recreativas en el agua como natación, juegos acuáticos, boga o remo, etc., así como en } \\
\text { las playas fluviales. }\end{array}$ \\
\hline Aptitudes y/o Restricciones \\
\hline $\begin{array}{c}\text { Aquellas secciones en que el río presenta mayores profundidades en su cauce. Las embarcaciones } \\
\text { deben ser capaces de movilizarse en aguas poco profundas. Playas de rodados dificultan estar y } \\
\text { caminar. }\end{array}$ \\
\hline
\end{tabular}




\begin{tabular}{|c|}
\hline Categoría 7 de Calidad del Paisaje \\
\hline Zona Preservación y Recuperación en Laderas y terrazas fluviales \\
\hline Actividades recomendadas \\
\hline $\begin{array}{c}\text { Prácticas de reforestación y/o recuperación de vegetación nativa. Aplicación de medidas de control } \\
\text { de la erosión, los movimientos en masa y la escorrentía. Desarrollo de proyectos de parques } \\
\text { acuáticos en áreas de pozos de extracción de áridos abandonados. }\end{array}$ \\
\hline Aptitudes y/o Restricciones \\
\hline $\begin{array}{c}\text { Zonas de ecosistemas frágiles, de reducida espacialidad o con destacada autenticidad, que } \\
\text { ameriten la reducción al mínimo de los impactos antrópicos. Exclusión de actividades antrópicas. }\end{array}$ \\
\hline
\end{tabular}

\begin{tabular}{|c|}
\hline Categoría 8 de Calidad del Paisaje \\
\hline Zonas de Urbanización Verde \\
\hline Actividades recomendadas \\
\hline $\begin{array}{c}\text { Urbanizaciones de baja densidad con plazas y avenidas. Instalaciones de apoyo recreacional en } \\
\text { áreas de parques de uso social masivo. }\end{array}$ \\
\hline Aptitudes y/o Restricciones \\
\hline $\begin{array}{c}\text { Zonas de rinconadas de menor insolación y vegetación nativa, por lo que las intervenciones deben } \\
\text { considerar especialmente el cuidado del medio ambiente. Adecuado para condominios de parcelas } \\
\text { de agrado. }\end{array}$ \\
\hline
\end{tabular}

\begin{tabular}{|c|}
\hline Categoría 9 de Calidad del Paisaje \\
\hline Zona de uso industrial \\
\hline Actividades recomendadas \\
\hline $\begin{array}{c}\text { Presencia e instalación de complejos industriales con uso de tecnologías limpias y manejo de RIL's, } \\
\text { con control de efluentes contaminantes. }\end{array}$ \\
\hline Aptitudes y/o Restricciones \\
\hline $\begin{array}{c}\text { Terrenos apartados del desarrollo urbano y áreas recreativas, con buena ventilación. Desarrollo de } \\
\text { vialidad ad-hoc, transito de productos y materia primas no congestionante. }\end{array}$ \\
\hline
\end{tabular}

\begin{tabular}{|c|}
\hline Categoría 10 de Calidad del Paisaje \\
\hline Zona de Cauces con Riesgo por Mov. en Masa e inundación \\
\hline Actividades recomendadas \\
\hline $\begin{array}{c}\text { Desarrollo de parques provistos de infraestructura de protección y mitigación, con sistemas de } \\
\text { control, mejoramiento y mantención de la funcionalidad de las medidas aplicadas. }\end{array}$ \\
\hline Aptitudes y/o Restricciones \\
\hline Áreas de cauces y bancos fluviales con exclusión de actividades socio-recreativas y productivas, y \\
de instalaciones ajenas a la prevención - estabilización.
\end{tabular}

Aplicando estos usos recomendados a las unidades de calidad homogénea de paisaje, expresados en función del mapa de unidades y subunidades geomorfológicas, se obtiene el siguiente mapa de propuesta de usos (Fig. 4). 


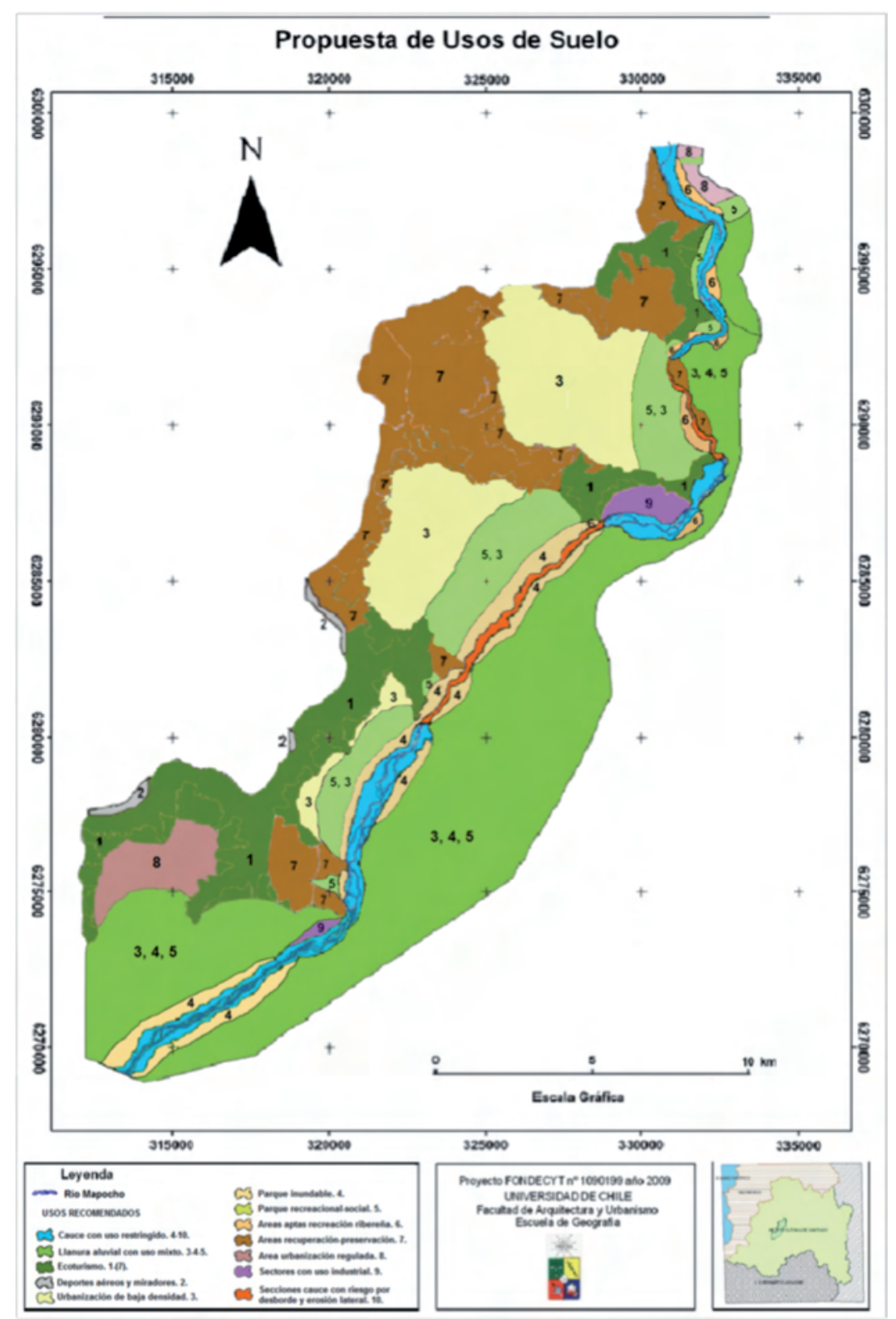

Fig. 4. Propuestas de uso de suelo.

\section{CONCLUSIONES}

En relación con el método empleado, este fue desarrollado para ambientes fluviales templado-mediterráneos del territorio español, por lo que revisadas las variables, criterios y categorizaciones consideradas para determinar la calidad y fragilidad intrínseca de cada unidad de paisaje, se le consideró apropiado para alcanzar una primera aproximación en este sentido en el territorio del corredor fluvial del río Mapocho inferior. No obstante, y como se expresa a continuación, se consideró apropiado enriquecer el análisis con variables que aportaran a mejorar los 
resultados, principalmente desde el punto de vista de su influencia en la dinámica del medio físico del área de estudio, aspecto relevante a la hora de establecer directrices para el ordenamiento territorial.

Respecto de su aplicación, considerados los parámetros propuestos por el modelo metodológico utilizado, se pudo establecer una alta concordancia espacial entre la calidad y fragilidad del paisaje y las unidades geomorfológicas diferenciadas. Sin embargo, se observó la falta de consideración de elementos componentes del sistema natural y de la intervención humana dentro del modelo, de gran relevancia en la dinámica hidro-morfológica, por lo que complementariamente se realizó un análisis de estos aspectos, cuyo resultado se cruzó con las categorías de calidad del paisaje para llegar a un mejor resultado. De este modo se logró definir y delimitar unidades geomorfológico-paisajísticas más acordes al contexto y dinámica natural, estableciéndose en algunos casos subdivisiones en función de alguna diferencia significativa encontrada.

En este sentido, los resultados de la aplicación de los criterios utilizados y las ponderaciones de los mismos según CENTENO et al. (1994), los que se expresan en la matriz correspondiente, permitieron establecer unidades de calidad de paisaje asociadas a delimitaciones geomorfológicas. Luego, incorporando el dimensionamiento del rol de las componentes naturales del paisaje en su dinámica evolutiva y de control de formas y procesos, se llegó a una caracterización y categorización de base distinta de las unidades geomorfológicas, lo que hizo posible establecer los tipos de actividades y usos más recomendables teniendo en cuenta los antecedentes y criterios utilizados.

Los resultados alcanzados, y que cartográficamente expresan unidades de manejo, permiten aportar, desde los puntos de vista planteados en esta investigación, principalmente referidos a las características del sistema natural del corredor fluvial del río Mapocho inferior, a un ordenamiento territorial sustentable para el área de estudio, la que constituye un espacio intercomunal superpuesto a un territorio fluvial de gran relevancia ambiental, tanto en sí mismo como en el contexto de inminentes cambios de uso, orientados principalmente hacia lo urbano.

En este sentido, los usos recomendados apuntan a destacar la favorabilidad de ciertos contextos geomorfológicopaisajísticos respecto de algunas actividades e instalaciones, así como a distinguir niveles de restricciones y recomendaciones producto de las características del sistema natural y los mecanismos que lideran su proceso evolutivo.

La determinación de la espacialidad y condición de cada unidad geomorfológicopaisajística resultante se encuentra implícita en la relación de las variables consideradas, tanto en la matriz de calidad total del paisaje (predefinidas por el modelo), como en la tabulación de la condición que imprime cada variable del medio natural y de intervención humana en el nivel de equilibrio morfodinámico presente $\mathrm{y}$ potencial, en tanto determinantes del uso recomendable.

Dada la escala de análisis empleada en el trabajo realizado, es claro que existen diferencias internas en algunas de las unidades diferenciadas, lo que se revela en la indicación de más de un uso recomendado para algunas de ellas. Producto de ello, al momento de determinar los usos recomendables en forma más precisa, posiblemente en un Plan Regulador Intercomunal a nivel del área de estudio, se requerirá realizar análisis y evaluaciones locales a mayor escala. 


\section{REFERENCIAS}

CENTENO, J.; FRAILE, M.; OTERO, M. y A. PIVIDAL, 1994. Geomorfología Práctica: Ejercicios de fotointerpretación y planificación geoambiental. Editorial Rueda, Madrid.

DE LUCA, F., 2010. Geomorfología y paisaje: Aporte al Ordenamiento territorial del corredor occidental del Río Mapocho. Comunas de Pudahuel y El Monte. Memoria para optar al Título de Geógraf., Facultad de Arquitectura y Urbanismo, Universidad de Chile. 120 pp. Inédito.

FERRANDO, F., 2010. Expansión urbana, PRMS y el corredor fluvial del Río Mapocho inferior. Revista Electrónica de Urbanismo $\mathrm{N}^{\circ} 22.13$ pp.

GÓMEZ OREA, D., 1994. Ordenación del Territorio. Una Aproximación desde el Medio Físico. Instituto Tecnológico Geominero de España. Editorial Agrícola Española. Madrid, España. 238 pp.

GRAF, W.L., 1988. Definition of floodplains along arid region rivers. In Baker, V.R.; Kochel, C.R. \& Patton, P.C. (Eds.): Flood Geomorphology, 231-242, Wiley, New York.

JUNK, W.J.; BAYLEY, P.B. \& R.E. SPARKS, 1989. The flood-pulse concept in river flood-plain systems. Special publication of the Canadian Journal of Fisheries and Aquatic Sciences, 106: 110127.

OLLERO,A., \& G.R.ROMEO, 2007. Las Alteraciones Geomorfológicas de los Ríos. OLLERO y ROMEO (Eds.): Estrategia Nacional de Restauración de Ríos de España, Ministerio del Medio Ambiente Universidad Politécnica de Madrid, España. $232 \mathrm{pp}$.

OLLERO, A., 2003. El Ebro quiere volver a ser libre. Una dinámica fluvial activa es la clave para que haya ríos vivos. Quercus, 213: 34-38.

TOCKNER, K.; MALARD, F. \& J.V. WARD, 2000. An extension of the Flood Pulse Concept. Hydrological Processes, 14: 2861-2883.

VÁSQUEZ, M., 2009. Hacia la sostenibilidad metropolitana del territorio desde la perspectiva ecológica. GIAUS - UPM. En: Jornadas Santiago Región Sustentable: Desafíos del Ordenamiento Territorial. http://www.uchilefau.cl/SisNot/ noticia_completa.php?top=832.

WILLIAMS, K.D.; SENIOR, C.A. \& J.F.B. MITCHELL， 2001. Transient climate change in the Hadley Centre models: the role of physical processes. J. Clim., 14: 2659-2674. 

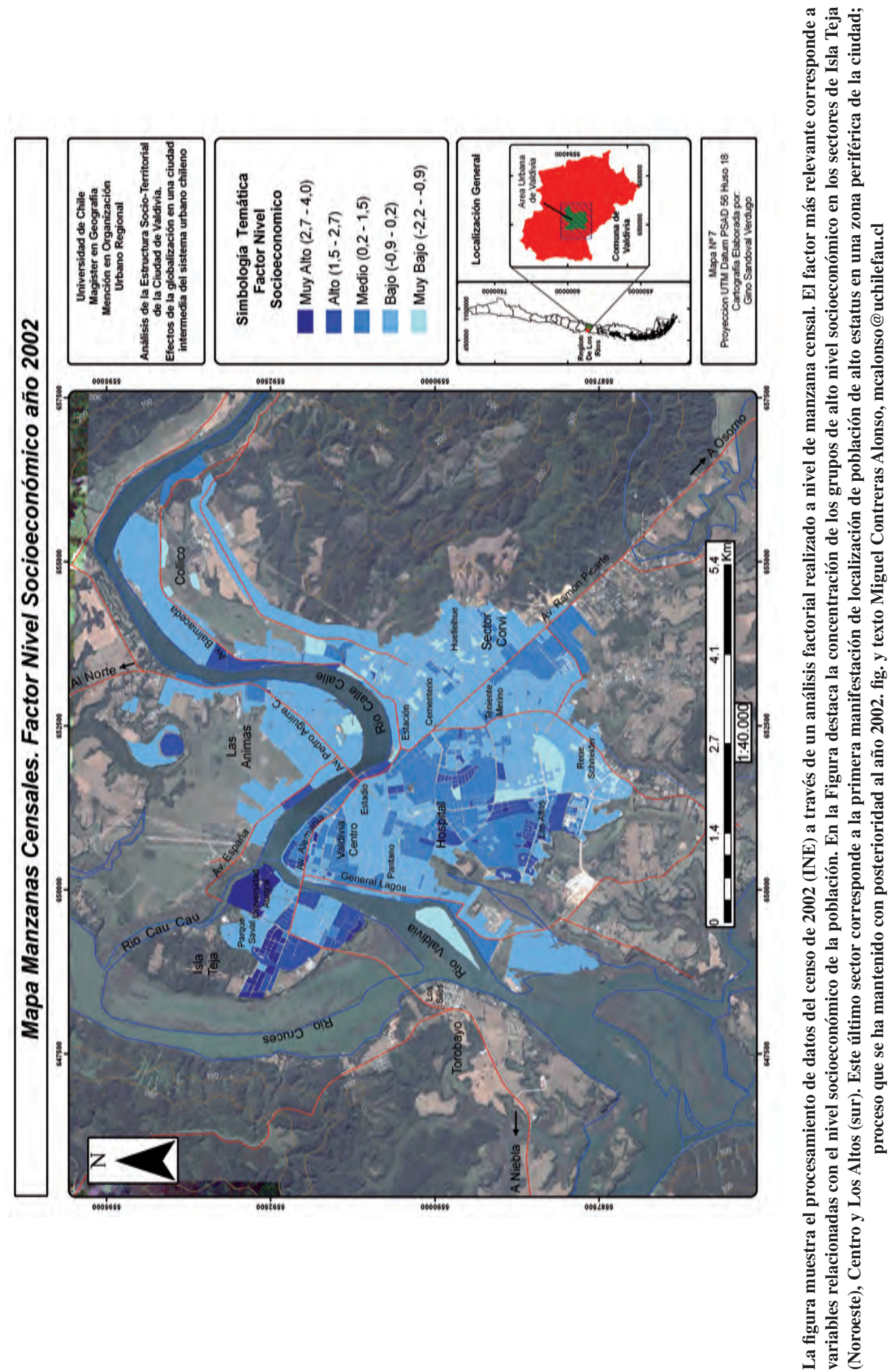